\title{
PETROL PUMP AUTOMATION SYSTEM
}

\author{
Arpita Nayal, Mahima Gaur, Tanisha Kashyap, Vartika Shukla \\ Department of ECE \\ Shri Ram Murti Smarak College of Engineering and Technology, Bareilly, India
}

Abstract - Petroleum is the mainstay of modern civilization. It is one of the nature's rare and valuable creations. Its formation takes millions of years and thus, it is necessary that its proper utilization must takes place. In the current scenario, petrol pumps are operated manually, comprising of a controlling unit to perform various tasks. These petrol pumps are time consuming, requires more man power, prone to malpractices and also there exist a probability of many human errors. Also, it is not possible to place petrol pumps in distant areas. The main aim of this paper is to deal with all such problems and thus, aims to develop an automated petrol dispensing system using RFID technology. Such a system enables a user to use a RFID based prepaid card to access petrol at such petrol pumps.

Whenever the user wants to fill the tank from the fuel dispenser, he has to enter the amount first and then place the RFID card near the RFID reader. Then the Arduino Uno reads the data from the RFID reader and performs the action according to the customer requirements and the amount is deducted from the user's card. RFID Based Automated Petrol Pump will hence improve the existing system by reducing human work and providing an auto guided mechanism to carry out the tasks consecutively. These systems are less time-consuming and highly reliable.

Keywords - RFID, Fuel Dispensing System, Arduino

\section{INTRODUCTION}

India became the fourth largest auto market in 2018 and was the seventh largest manufacturer of commercial vehicles in 2018. Around 2.17 million cars were sold in India in 2017-18. According to the Ministry of Road Transport and Highways, India's Registered Motor Vehicles: Total from 1951 to 2017 in the chart:

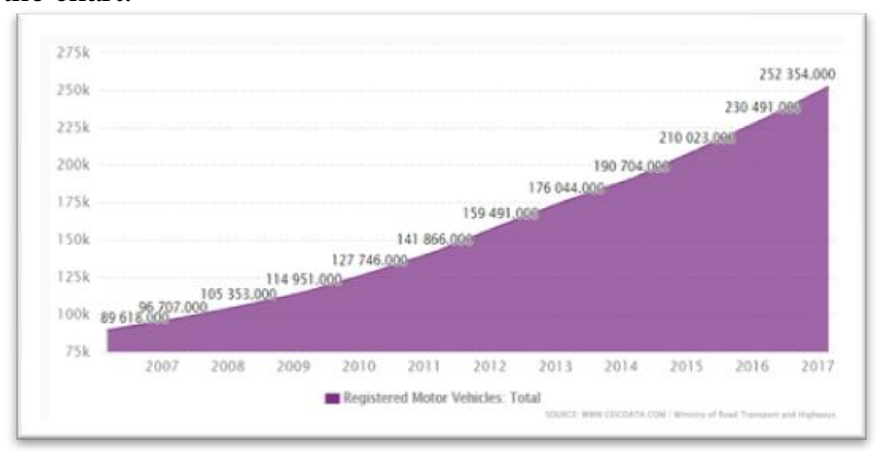

In the recent years, the increase in the number of vehicles in India has led to a huge increment in the need of petroleum as well.

The consumption volume of petroleum products in India was estimated to be approximately 201.9 million metric tons in fiscal year 2018. The country was ranked third with regard to primary energy consumption across the globe.

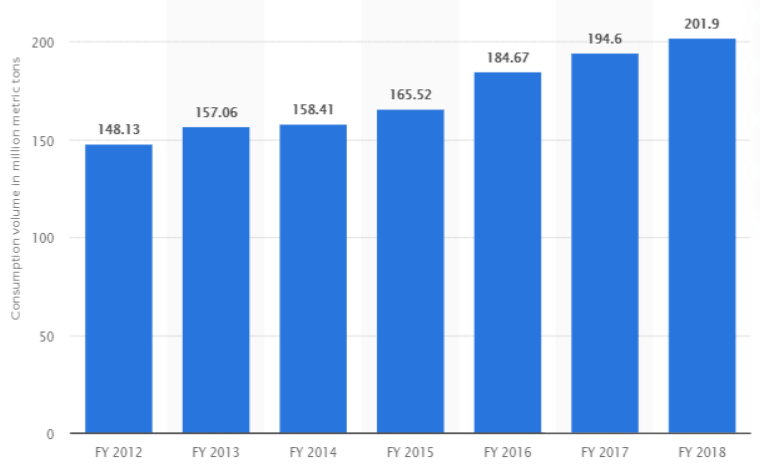

Petroleum being a non renewable resource is present in a limited quantity. Its formation takes millions of years and it cannot be replaced rapidly enough to cope up with its consumption. Thus, it is extremely crucial to ensure the right utilization and consumption of petroleum so as to preserve it for future generations as well (Kulkarni and Tawar et al.,2011).

Also, dispensing fuel to this huge number of vehicles in India has caused numerous complications. A long queue in front of a petrol pump due to huge rush at the station is a common scenario. This leads to wastage of valuable time. The operation in these pumps is completely manual which leads to various malpractices such as delivering less quantity to the customers and adulteration of fuel.

Thus, automation of petrol pumps is quite necessary to deal with all these modern era problems.

The main aim of the project is to design a system which is capable of automatically deducting the amount of petrol dispensed from user card based on this RFID technology. Whenever the user wants to fill the tank from the fuel dispenser, firstly he would have to enter the amount using a keypad and then bring the RFID tag near the RFID reader so as to verify the user. Then the Arduino Uno reads the data 
from the RFID reader and performs the action according to the customer requirements and delivers fuel to the vehicle. Therefore, the amount will be deducted automatically from the user card.

\section{LITERATURE REVIEW}

This system uses RFID technology, where RFID stands for Radio Frequency Identification, which is an automatic identification technology. It is used for to retrieve and store data on to RFID Tags without any physical contact (Patil Aishwarya M., Phuke sayali J., Tapase snehal B., et al.,2016; Fatah Chetouane et al. 2015).

RFID comprises of: RFID Tag, RFID Reader and Database Management System.

RFID tag is a micro chip having an antenna. The chip stores the Electronic Product Code (EPC) of the product, which is a unique number used for the identification of a specific item.

RFID reader is used to gather the data from a tag using radio waves.

Reader's antenna transmits EM waves which are received by tag's antenna. Then, the tag transmits this data back to the reader. Data collected is then transferred to a host system where it is stored in a database.

\section{PROPOSED IDEA}

This system is using RFID technology where each user will be having a rechargeable RFID card. These cards consist of RFID tags having unique verification codes. The RFID reader captures the digital data encoded in these tags.

When a customer brings the card close to the reader, it captures the data and then sends the corresponding signal to the microcontroller. The microcontroller stores details of various cards and thus, compares the information captured to check if both the details match or not. If it matches then according to the amount entered by the user, the microcontroller activates the relay driver for that particular amount of time and the desired amount is dispensed into the tank. And therefore, the amount is deducted from the user's card (Wavekar Asrar A., Patel Tosif N et al., 2016).

\section{FLOW CHART}

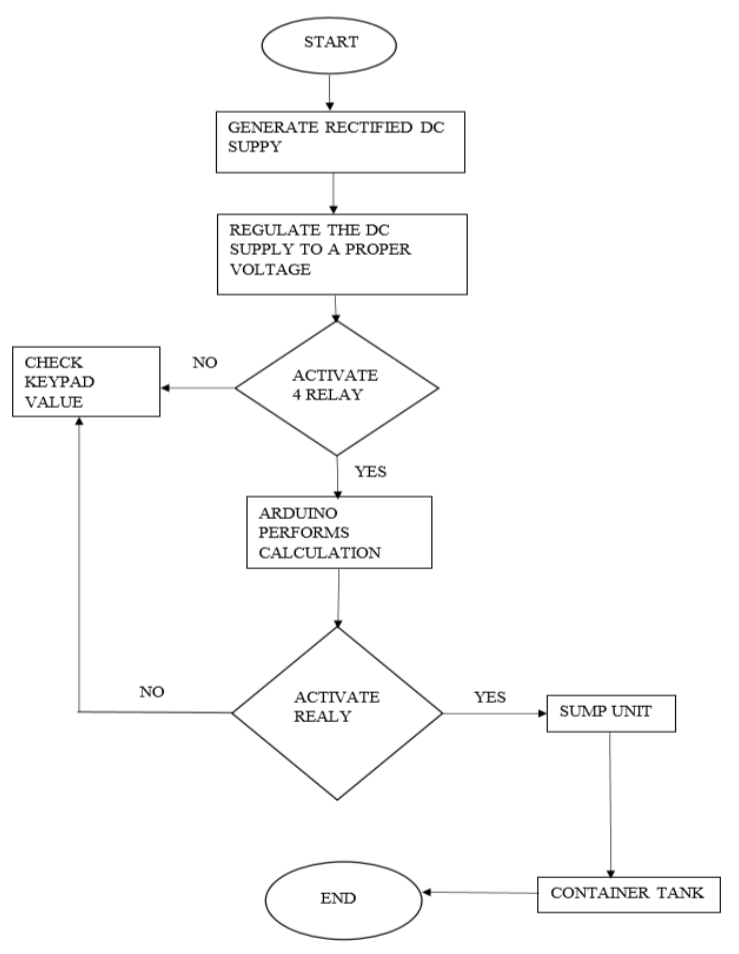

\section{HARDWARE COMPONENTS}

1. RFID tag

2. RFID reader

3. Arduino UNO

4. Transformer (9-0-9 V step down)

5. Diode 4007

6. Capacitor (2200uF)

7. Voltage Regulator IC 7809

8. PCB

9. Relay 6V

10. n-p-n transistor

11. Keypad

12. DC pump

\section{WORKING}

In this, we have made a petrol bunk using the RFIDs in addition with the Arduino UNO.

The proposed model works in 2 sections: Analog and Digital. The analog part deals with the measurement of time, quantity and amount for the product in dealing and the digital parts works for the SUMP (suction and pump) unit.

The model here works for three different amounts of money $=$ 100, 200 and 300.

The data for each amount is fed in a separate RFID tag and the account of their respective frequencies is stored in a RFID reader. 
The RFID works at a specified frequency of EM waves and as soon as the frequency is matched with the reader, the reader reads the amount (frequency) specified and actuates the Arduino to calculate time and quantity for the given amount. The Arduino signals the motor and the dispensing is done. It contains five relay switches, among which four enables the choice to the user to enter up to 4 digit amount and one relay is used to switch ON and OFF the DC motor.

The SUMP unit sucks up the desired fuel and pumps it in the container tank.

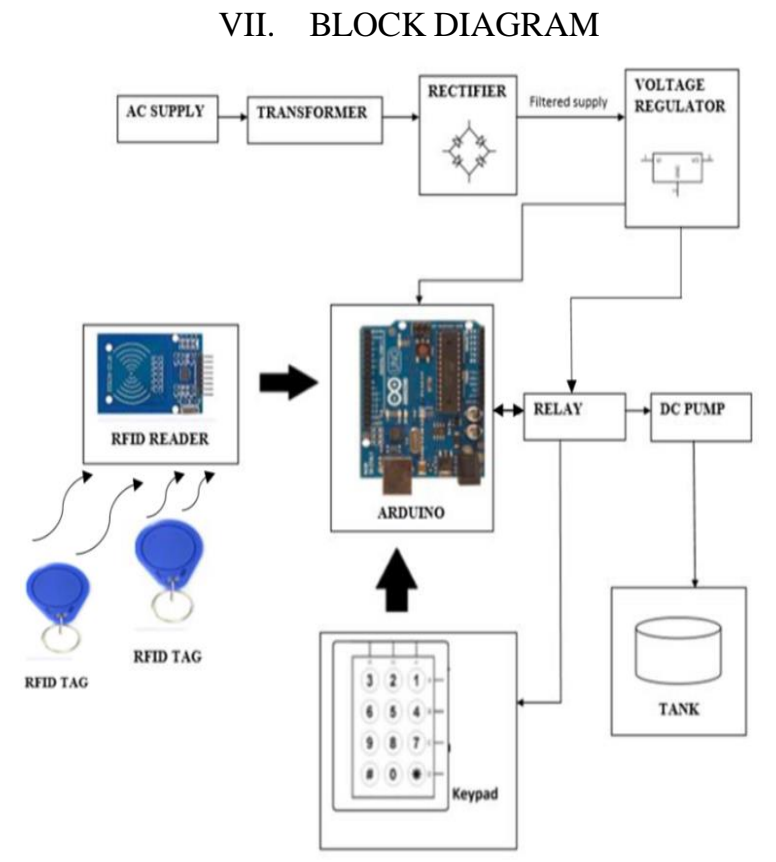

AC SUPPLY: We have used the $12 \mathrm{~V}$ ac supply from the source.

TRANSFORMER: A 9-0-9 V step down transformer is used in order to step down the Voltage to $9 \mathrm{~V}$ ac supply. A step down is made so as to protect the wires of the prototype from burning.

RECTIFIER UNIT: A full wave bridge rectifier is made to convert the AC supply into DC using diode 4007. Later the same supply is fed to the connection of capacitors where the ripple factor is removed from the converted supply i.e. the supply is made smooth.

VOLTAGE REGULATOR: The filtered supply is then put to the voltage regulator IC 7809 where any further noise or disturbance is removed and an accurate positive DC supply is later made through the circuit.
RELAY: The model uses 5 relays in total. 4 are used to switch $\mathrm{ON}$ the numeric logic digits through the user gets a possibility of entering 4 digit amount. The left out relay is joined by Arduino UNO and when the Arduino calculates the time and quantity for the dispensing of petrol, the relay switches the logic for the DC motor to turn it $\mathrm{ON}$ or OFF.

ARDUINO UNO: The outputs of the voltage regulator is supplied to the Arduino UNO where the Arduino gets the electric pulses from the Voltage regulator and the relay gives the information about the amount entered. In addition with the information the relay circuits which controls the AC devices through the DC power.

KEYPAD ARRAY: The keypad array is used to enter the amount and is connected with the relay circuits.

RFID READER: The RFID reader has a radio transponder that acts as an antenna that uses EM fields to identify the signals corresponding to the RFID tag.

RFID TAG: It holds certain frequency that contains data that can be transmitted with the same frequency.

SUMP: It is the suction and pump unit that sucks the calculated and required fuel and pumps it in the container tank.

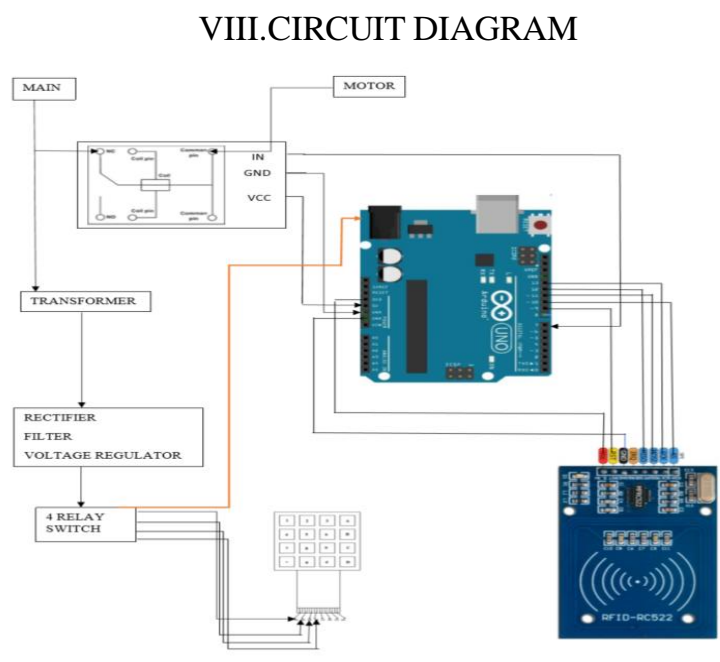

VIII. ADVANTAGES

In our project, RFID system dispenses the accurate amount of fuel ensuring that the customer gets the right quantity of fuel and no adulteration should happen at the petrol pump.

Petrol pump automation through RFID technology provides the following advantages:

- These machines are completely controlled by 
automation, meaning it can't be used manually by the sales person. The quantity which is ordered by the customer will be entered by him only and the fuel dispensing will cease once the quantity ordered is delivered inside the tank.

- Man power is reduced because of automated selfservice.

- $\quad$ Easy access and save time in the petrol bunk.

- Avoids misconceptions and arguments.

- Due to use of RFID system, robbery of the fuel is avoided.

- Accuracy in the amount of petrol dispensed.

- The customers can use prepaid cards for payments at these petrol pumps, allowing them to keep record of all the transactions done.

- Low power consumption.

\section{FUTURE SCOPE}

It has been observed that the proposed system is extremely beneficial as it provides a secure and cashless system, which avoids fuel thefts.

This proposed unmanned automated fuel dispensing system can be further enhanced by making it password protected so that only the person to whom the RFID card belongs can use it to access petrol at stations. In this, each user will be having a unique pin for their respective RFID cards. Whenever the user wants to fill petrol, he would have to enter this pin. If he enters the correct pin, he will be asked to enter the amount and further process will take place. On the other hand, if the entered pin is wrong, he will be given two more chances for the same, failing which access will be denied which raises the alarm. This will help to authenticate the user and thus will improve security as no user could use another person's card illegally (Wavekar Asrar A., Patel Tosif N et al., 2016).

Another problem that can be dealt with is adulterations at petrol pumps. This can be achieved by conducting density tests. Hydrometers and digital meters can also be used to check the density of the fuel sample. The adulteration causes the change in the density that can be correlated with then adulteration. Hence, the right quality can be ensured by maintaining the right density of petrol. These devices can be inserted in the underground storage tank. It gives the reading of product density in the display unit at any time. Generally, when company officials visit a petrol pump, they can check the density using this display unit.

\section{CONCLUSION}

The above mentioned idea proposes to eradicate all the shortcomings of the manually operated petrol stations by replacing them with automated ones. RFID is a very versatile technology and it can be efficiently used in this real time application.

The proposed idea consist of certain goals like ensuring right amount of fuel dispensing, removing human errors by the use of RFID cards and ensuring customer's trust for a fair sale of the product.

These automated petrol pumps provide a lot more benefits as they reduce man power with the automated self service at the stations. With this simple technology in use any person can easily access petrol at these stations.

Apart from this, these systems are less time consuming compared to the traditional ones. The technology proposed is very cost efficient and has low power consumption as well, which sets a major benchmark in today's scenario.

\section{ACKNOWLEDGEMENT}

We owe special debt of gratitude to Ms Namrata Gupta, Asst. Prof. Department of Electronics \& Communication \& Engineering, SRMS College of Engineering \& Technology, Bareilly for her constant support and guidance throughout the course of our work. Her sincerity, thoroughness and perseverance have been a constant source of inspiration for us. It is only her cognizant efforts that our endeavors have seen light of the day.

We also take the opportunity to acknowledge the contribution of Ms Nazia Parveen, Head Department of Electronics \& Communication \& Engineering, SRMS College of Engineering\& Technology, Bareilly for her full support and assistance during the development of the project.

We also do not like to miss the opportunity to acknowledge the contribution of all faculty members of the department for their kind assistance and cooperation during the development of our work. Last but not the least, we acknowledge our friends for their contribution in the completion of the project.

\section{REFERENCES}

[1] Kulkarni Amruta M., and Tawar Sachin S., (2011), Embedded Security System Using RFID \& GSM Module, International Journal of Computer Technology \& Electronics Engineering, Volume 2, Issue 1, (Pg164-168).

[2] Patil Aishwarya M., Phuke Sayali J, Tapase Snehal B., (2016), College Access and Student Attendance using RFID technology, Volume 5, Issue 1.

[3] Wavekar Asrar A., Patel Tosif N., Pathan Saddam I., Pawar H., (2016), RFID Based Automated Petrol Pump, International Journal for Scientific Research \& Development, Volume 4, Issue 1.

[4] Jadhav Aniket H., Pawar Rajan S., Pathare Priyanka M, Pawar Kishori D., Patil P., (2014), Multi-Automized Fuel 
Pump With User Security, International Journal Of Science And Technology Research, Volume 3, Issue 5.

[5] Jaska P., Johnson D.B.A., Nalla J., Reddy N.V.K. and Tadisina R., (2010), Improved customer service using RFID technology, Review of business Information Systems, Volume 14 , Issue 3.

[6] Jadhav A., Patil L., Sonawane A.D., (2017), Smart Automatic Petrol Pump System, International Journal Of Science Technology and Management, Volume 6, Issue 4.

[7] Fatah Chetouane, (2015), An Overview on RFID Technology Instruction and Application, IFAC-PapersOnLine, Volume 48, Issue 3, (Pg 382-387).

[8] Nang Khin, Su Yee, Theingi, Kyaw Thiha, (2015), Fuel Monitoring and Electronics control of Dispenser for Fuel Station, International Journal of Engineering and Techniques, Volume 1, Issue 4.
[9] Cekerevac Z., Matic S., Duric D. and Celebic D., (2006), Fuel dispenser control system as the technical solution for preventing non-authorized fuelling, International Scientific Conference devoted to Crises Situations Solution in Specific Environment, Zilina.

[10] Fawzi Al-Naima (2015), Design of an RFID Vehicle Authentication System, International Journal of Scientific and Technological Research, Volume 1, Issue 7.

[11] Satyasrikanth P., Penna Mahaveer, Reddy Dileep (2016), Automatic Toll Collection System using RFID, International Journal of Computer Science and Mobile Computing, Volume 5, Issue 8, (pg.247 - 253).

[12] N. Jeevagan, P. Santosh, R. Berlia and S. Kandoi, (2014), RFID based vehicle identification during collisions, IEEE Global Humanitarian Technology Conference (GHTC), San Jose, CA. 